\title{
A client's perspective of design for manufacture and assembly in the UK water industry
}

Lyndon Trinder BEng (Hons), MSc, CEng, MICE Civil Engineer, Engineering, United Utilities, Warrington, UK

John Browne BEng (Hons), IEng, MICE

DFMA Programme Manager, Innovation, United Utilities, Warrington, UK (corresponding author: john.browne@uuplc.co.uk)
Kieran Brocklebank BSC (Hons), MSc, McIPS Head, Innovation, United Utilities, Warrington, UK

\begin{abstract}
UK water companies are under increasing pressure from regulators, customers and tightening legislation to deliver more for less. The design for manufacture and assembly (DFMA) has proven to deliver efficiencies in other sectors including construction and manufacturing. Faced with increasing financial constraints, many water industry companies are now looking to gain the benefits of DFMA. A study was undertaken to summarise the processes adopted by one of the UK's largest water companies to achieve the benefits of DFMA. The company sees DFMA as an efficiency strategy in delivering its investment programme. To enable, lead and drive this strategy, the company implemented a client-led DFMA change programme supported by collaboration with key supply partners including contractors, consultants and suppliers. DFMA forms part of a wider strategic shift at the company comprising better digital data management and a design-and-build contract strategy. These changes will drive efficiencies across the investment programme and optimise the future operation and whole-life cost of the company's asset base. This paper describes the company's strategic shift to a DFMA delivery model and culture. It covers the who, what, why and how of the DFMA programme.
\end{abstract}

\section{Introduction}

As water companies seek efficiencies within their investment programmes in response to regulatory targets and customer commitments, design for manufacture and assembly (DFMA) has become a hot topic. Water companies are seeking the improvements seen in manufacturing and other construction sectors who have adopted DFMA delivery models. The water industry is becoming more active in its attempts to adopt and utilise these models (Figure 1).

This paper discusses how United Utilities (UU; Figure 2) is embedding and delivering DFMA on projects across its investment programme. It discusses why UU shifted to greater DFMA use within their 2015-2020 (Asset Management Plan 6 (AMP6)) investment cycle. UK water companies agree on spending programmes in 5-year cycles with the Water Services Regulation Authority, Ofwat. The proposed spending is outlined in the company's AMP. AMP5 ran from 2010 to 2015 and AMP6 from 2015 to 2020 (Figure 2).

UU began exploring off-site construction in AMP5 and delivered success on several independent projects. Off-site construction was core to overcoming the significant scheduling challenges of these projects while maintaining defined cost and quality criteria. These projects demonstrated the benefits of off-site construction and suggested that these could be repeated elsewhere. However, offsite construction was not the default choice with off-site solutions used on $<10 \%$ of all projects. UU recognised that their supply chain had limited DFMA capability and client leadership was required to encourage DFMA.
In 2013, UU created a project to promote off-site construction, collect information off-site and help create an off-site-friendly environment. This project set out to improve UU's position and maturity in relation to DFMA principles within the UK water industry, maximising off-site opportunities in the remainder of AMP5 and promoting continuous improvement. The project was also preparing UU for a step change in the use of DFMA in AMP6. The AMP5 project proved the concept of adopting off-site construction as a delivery method. It focused the potential efficiencies in time, cost, quality, customer, waste and health and safety (Figure 3).

In 2014, UU agreed on a challenging AMP6 investment programme with Ofwat. During AMP6, UU will invest $£ 3 \cdot 8$ billion across 262 projects with a direct construction spending of $£ 2.4$ billion. DFMA was included as a key initiative to obtain cost and time efficiencies in this spending. In addition to this, UU recognised the wide range of benefits DFMA delivers and how these contribute to UU's core values: customer focus, integrity and innovation (Figure 4).

\section{The DFMA programme strategy}

UU's AMP6 contract strategy is design and build with few tier 1 contractors competing to win the work. This type of contract does not encourage contractor collaboration nor the upfront investment in innovation. UU recognised that DFMA would not happen by coincidence or naturally. This realisation led to the creation of a central UU DFMA programme, with direct senior sponsorship from the UU Innovation team and executive endorsement at the chief executive officer and directorate levels. A virtual team led 
A client's perspective of design for manufacture and assembly in the UK water industry

Trinder, Browne and Brocklebank

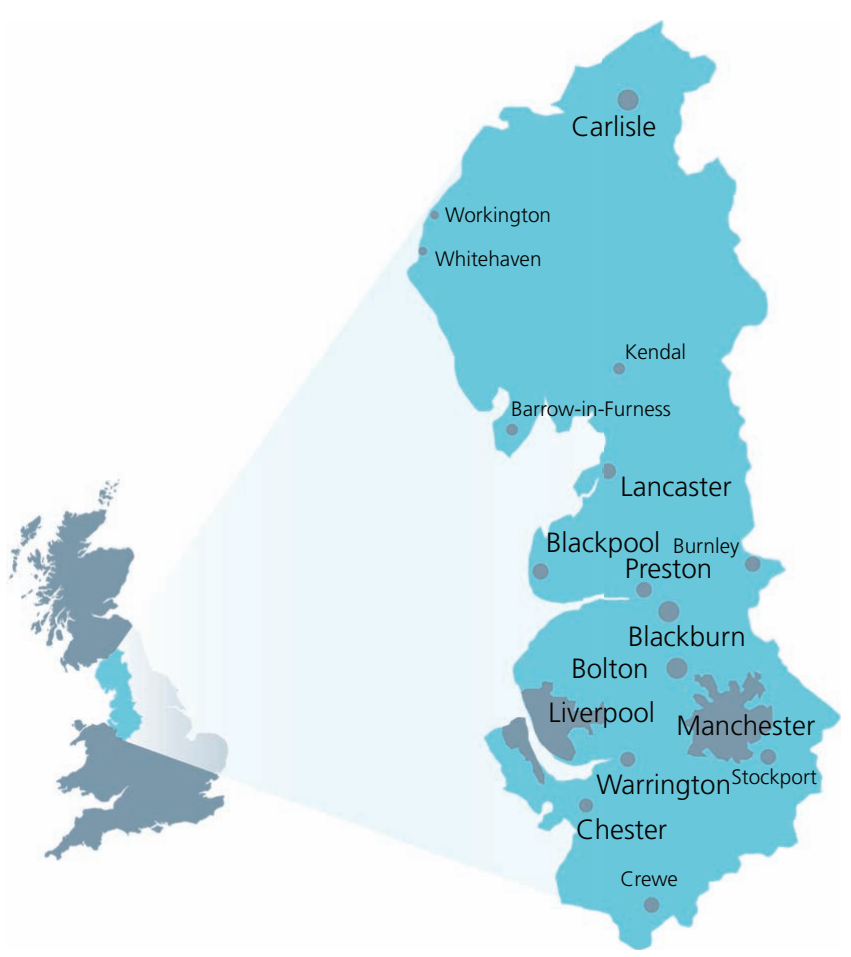

Figure 1. Diagram showing UU's regulated operational area across the UK

by a programme manager was created and funded to embed and deliver DFMA in AMP6.
UU's board endorsed the DFMA programme's business case and strategy to deliver the business change required to make DFMA the default project delivery method (Figure 5). A DFMA delivery model would utilise standard off-site products with product information readily available to both UU and framework partners through a central library. UU set time-saving (5000 persons) and cost-saving ( $£ 50$ million) targets for the DFMA programme.

UU incorporated DFMA into their AMP6 framework strategy; in part, the AMP6 framework tenderers were assessed against their DFMA technical skill and potential to deliver by DFMA. A named DFMA champion representative from each partner was a contractual requirement. The programme would work closely with these partners drawing on their knowledge to enable DFMA.

The DFMA programme has four key areas of work.

Embed a DFMA-focused culture.

- Implement a hub-and-spoke model (Figure 6) with the client leadership drawing expertise from partners and disseminating knowledge across the programme to facilitate continuous improvement and knowledge sharing.

- Define DFMA in the context of UU and the wider water industry.

- Upskill and educate employees and the supply chain with DFMA-focused training.

- Promote change in project delivery processes to mandate DFMA, facilitating opportunities and reducing risks.

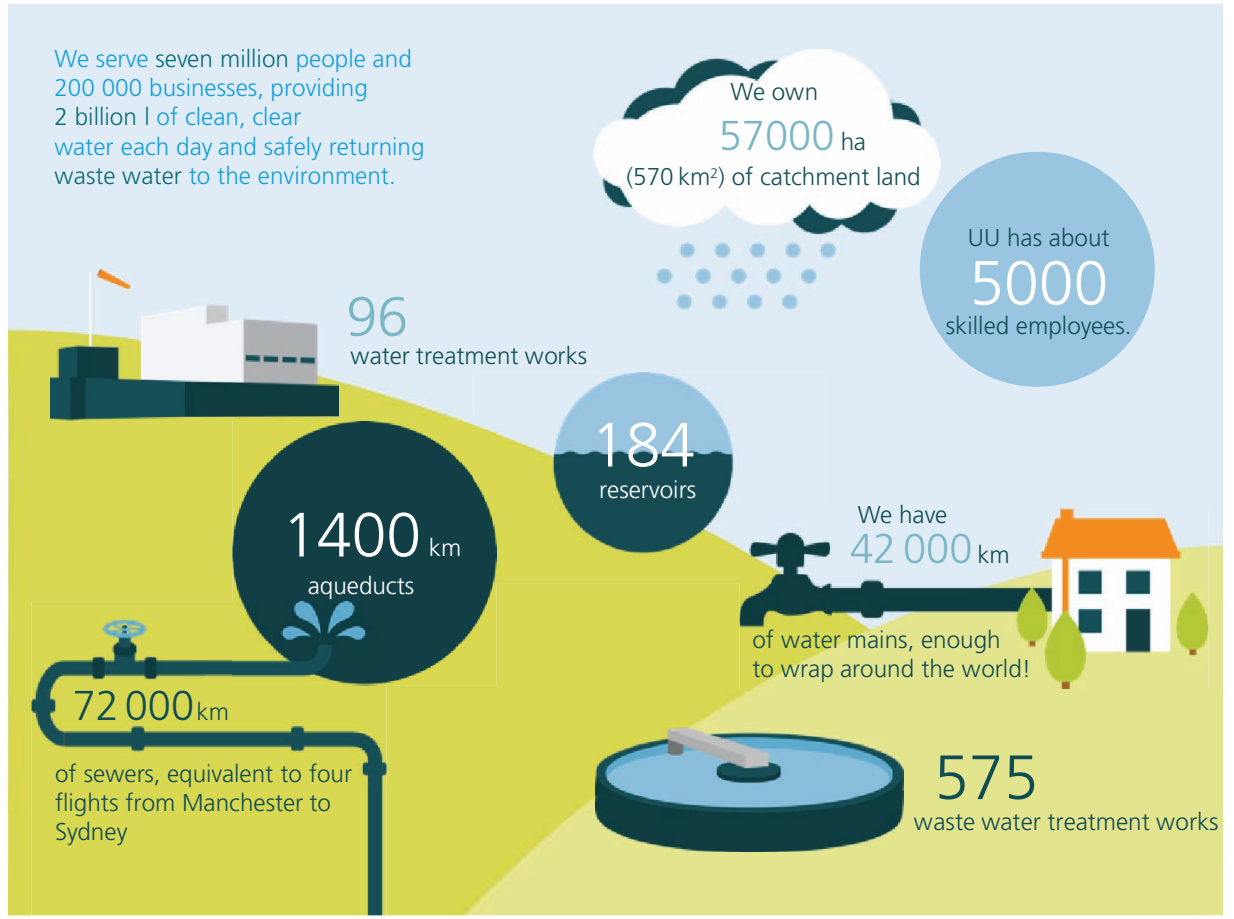

Figure 2. Infographic showcasing the scale of UU's asset base 


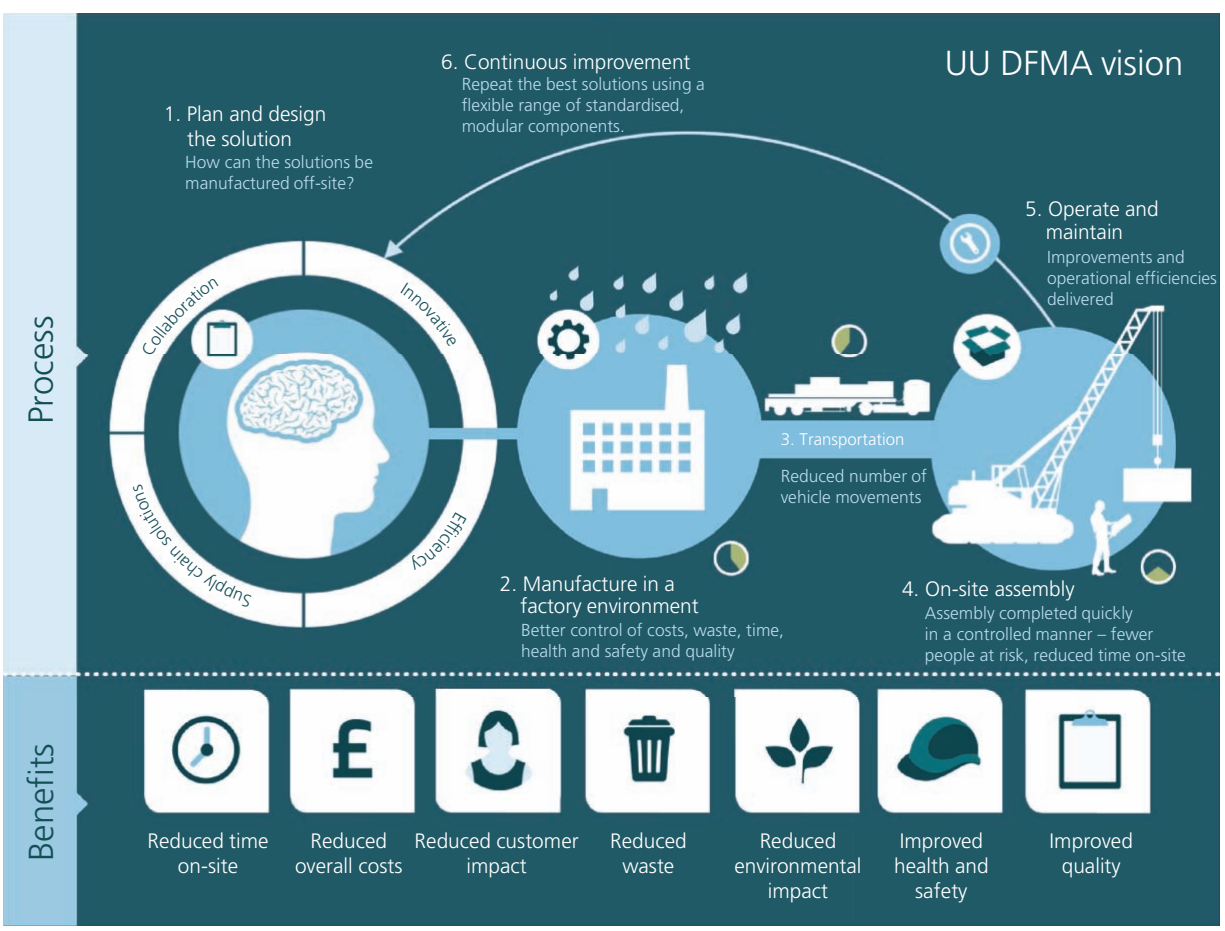

Figure 3. UU's DFMA strategy

- Collaborate with both UU's direct and wider supply chain.

- Promote DFMA successes through sharing of project case studies and a management dashboard for senior leadership.

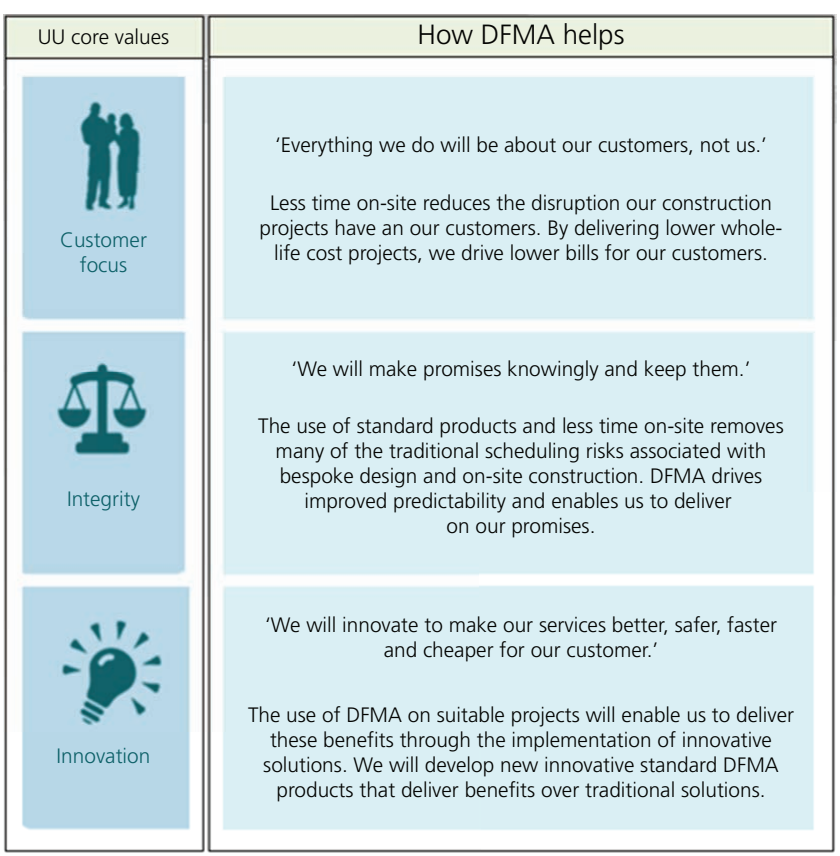

Figure 4. UU's core values
Increase the use of DFMA.

- Make it easier to implement DFMA. Identify and remove blockers.

- Encourage DFMA offers from the supply chain through a contractual key performance indicator (KPI).

- Collaborate with UU partners and the wider supply chain to encourage DFMA offers.

- Create, manage and champion a central library of DFMA knowledge for UU's supply chain to use.

- Influence internal stakeholders within project delivery to ensure that DFMA is embedded at the project level. The stakeholders included engineering, commercial and project management.

- Develop and deliver DFMA 'standard' products.

- Find opportunities to repeat solutions and increase standardisation across projects.

- Define standardisation within UU and where this will deliver value over existing products.

- Plan and deliver a programme of product development to deliver outlined benefits supported by collaborative planning from UU partners.

- Develop standard products in conjunction with partners.

- Incentivise partners to develop standard products.

- Optimise existing standard solutions to reflect modern DFMA principles. 


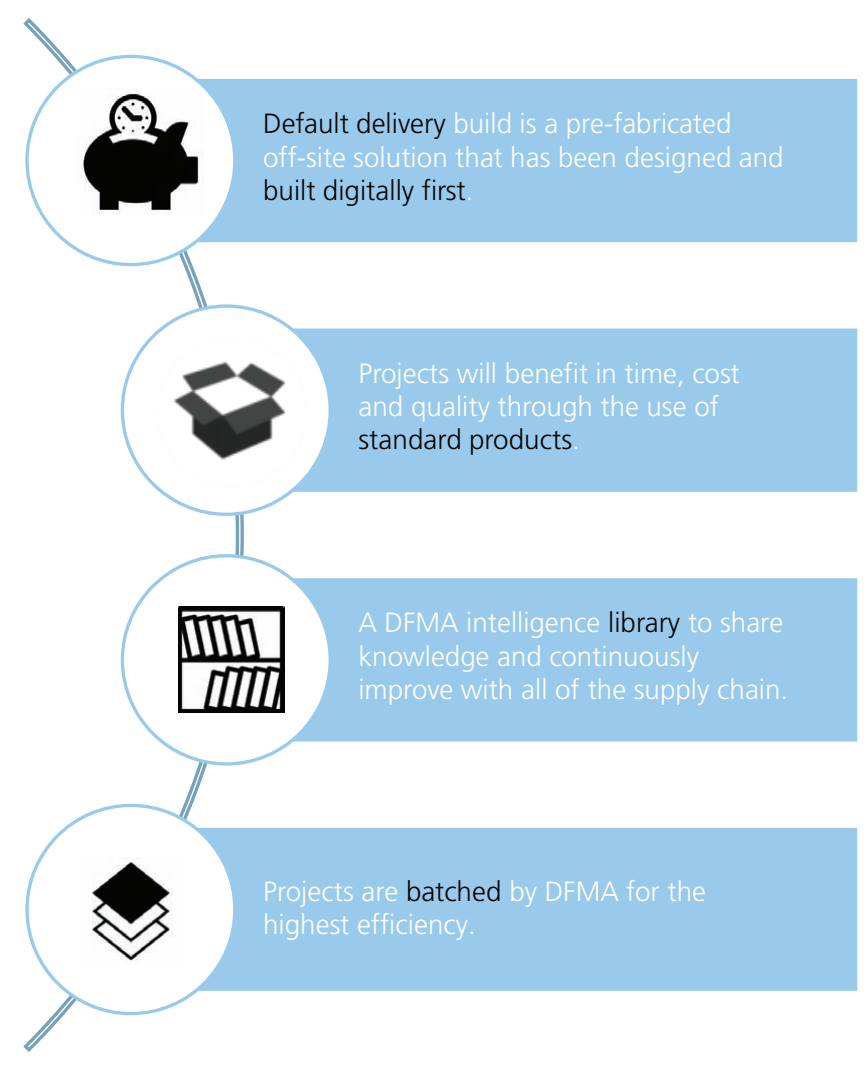

Figure 5. The key DFMA programme deliverables as agreed with the UU board

- Monitor and drive continuous improvement.

- Create a process to identify, communicate and deliver DFMA opportunities centrally by the DFMA programme.
- Build greater understanding of, and data on, the efficiencies of using DFMA. In particular, collect time, cost and quality data across the programme.

- Collect case studies on DFMA products to support communications and knowledge sharing.

- Create and use a management information dashboard to monitor programme progress, and facilitate the analysis of programme deliverables.

- Use information to target areas for improvement, and identify where DFMA could be used on future projects.

These key areas were to deliver several elements that were seen as high-value by UU such as reduced variety of design to increase common solutions and familiarity. This would be justified by an evidence-based approach supporting the benefits of DFMA, with information collected centrally by the DFMA programme. As safety is a critical success factor, the DFMA programme looked to exploit off-site safety benefits and ensure that the projects used the safest available methods and technologies.

\section{Defining DFMA}

DFMA language was a challenge across the industry. A common lexicon of terms and definitions did not exist (e.g. What is a product? What is off-site? What is an assembly?). To resolve this locally, UU developed and used a fixed naming convention that complemented UU's existing asset management systems.

Originally, a matrix was developed detailing ten DFMA product types (Table 1). These ranged from parts to complete assets based on the extent of work undertaken off-site and the level of integration between mechanical, electrical and civil components. This matrix was tested across UU and UU's partners. Feedback confirmed the matrix to be overly complex, adding little value in moving UU towards greater DFMA use. The need to define the differences

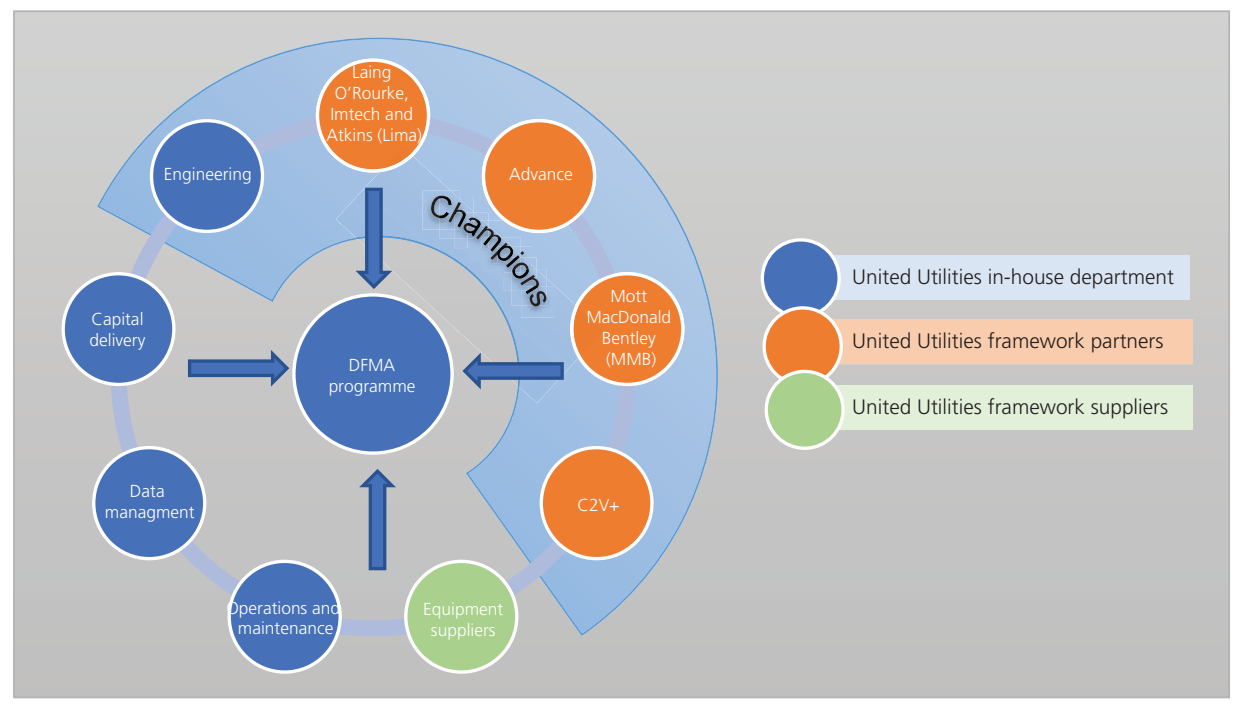

Figure 6. UU's hub-and-spoke model used by the DFMA programme to engage collaborative working and knowledge sharing 
between parts, components and products was less important in comparison to product maturity. Consequently, a simplified method for describing products was derived based solely on their maturity. Four defined levels of maturity were used to classify a DFMA product (Figure 7). A DFMA-focused library of the best practices, examples, knowledge and, ultimately, standard products would support this four-level categorisation.

\section{Procurement challenges}

During AMP5, supply chain expertise was crucial in understanding what DFMA could be achieved and this helped UU understand potential strategies for AMP6. The AMP6 programme minimised the use of equipment frameworks; not only did this minimise commercial management of frameworks, but it also opened UU to wider innovation and efficiencies by enabling delivery teams to utilise different suppliers not previously available. This increased the options for potential suppliers with DFMA specialists.

In previous AMPs, UU would generally complete $80 \%$ of the design with a direct influence on solution specifics. The AMP6 delivery model was based on design and build. The partner would prepare an initial design for tendering, which, if successful, would be developed once the contract was awarded and subsequently constructed. In this model, UU has less direct design influence. Subsequently, in this model, UU cannot detail the use of specific DFMA solutions but only influence them. To mitigate this, strategic levers were embedded within the framework contract and engineering standards to mandate the use of the DFMA where practicable.

A number of procurement challenges arose from this strategy. A key challenge is the need for partners to have competitive prices to win the work. This has been identified as a hurdle to DFMA at the contractawarding stage due to the narrow time frames available. Partners elected only to bring DFMA forward if it was definitively the best solution or if they were willing to gamble on it being a competitive tendering advantage. During challenging tender periods, partners in conjunction with suppliers suggested there was not enough time to develop a tender return with the requisite high confidence and low risk.

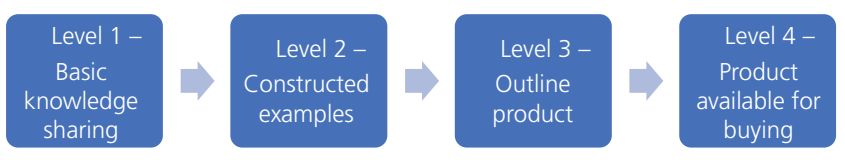

Figure 7. Description of the library levels employed to rank product maturity and describe a products' use of DFMA

Table 1. Original DFMA naming proposal showcasing the vast variations in potential off-site activity and part integration for DFMA products

\begin{tabular}{|c|c|c|c|c|}
\hline $\begin{array}{l}\text { Off-site } \\
\text { category }\end{array}$ & Category & Definition & Examples & Asset type \\
\hline $\begin{array}{l}\text { Standard } \\
\text { product }\end{array}$ & $\begin{array}{r}\text { Standard } \\
\text { product }\end{array}$ & $\begin{array}{l}\text { Integrated standard design comprising subassemblies, built } \\
\text { and tested as an integral module off-site, with agreed } \\
\text { supply arrangement }\end{array}$ & Booster station & $\begin{array}{l}\text { Pre-engineered } \\
\text { unit }\end{array}$ \\
\hline $\begin{array}{l}\text { Product } \\
\text { subassembly }\end{array}$ & $\begin{array}{l}\text { Product } \\
\text { subassembly }\end{array}$ & $\begin{array}{l}\text { Major element of standard product, assembled as a } \\
\text { subassembly and fitted on-site as stand-alone component; } \\
\text { agreed supply arrangement }\end{array}$ & ICA backboard & $\begin{array}{l}\text { Pre-engineered } \\
\text { unit }\end{array}$ \\
\hline $\begin{array}{r}\text { Modular civil } \\
\text { component }\end{array}$ & $\begin{array}{r}\text { Modular civil } \\
\text { component }\end{array}$ & $\begin{array}{l}\text { Major structural components made off-site from precast } \\
\text { concrete and stitched together through a jointing system to } \\
\text { form the civil structure }\end{array}$ & Twin wall section & $\begin{array}{l}\text { Standard } \\
\text { scalable design, } \\
\text { bespoke to site }\end{array}$ \\
\hline $\begin{array}{l}\text { Modular M } \\
\text { and } \mathrm{E} \\
\text { subassembly }\end{array}$ & $\begin{array}{l}\text { Modular M } \\
\text { and } \mathrm{E} \\
\text { subassembly }\end{array}$ & $\begin{array}{l}\text { Major subassembly housing mechanical, electrical, } \\
\text { instrumentation, control and automation (MEICA) components } \\
\text { with integrated structural steel support framework }\end{array}$ & Pipe rack or pump skid & $\begin{array}{l}\text { Standard } \\
\text { scalable design, } \\
\text { bespoke to site }\end{array}$ \\
\hline $\begin{array}{l}\text { Integrated } \\
\text { modular } \\
\text { asset }\end{array}$ & $\begin{array}{l}\text { Integrated } \\
\text { modular } \\
\text { asset }\end{array}$ & $\begin{array}{l}\text { Complete MEICA assembly including process tanks within a } \\
\text { structural steel framework, assembled and manufactured } \\
\text { off-site as a complete unit, transported in parts and } \\
\text { reassembled on-site }\end{array}$ & Integrated storm tank & Bespoke unit \\
\hline $\begin{array}{l}\text { Specialist } \\
\text { supplier } \\
\text { module }\end{array}$ & $\begin{array}{l}\text { Specialist } \\
\text { supplier } \\
\text { module }\end{array}$ & $\begin{array}{l}\text { Supply chain solution to specified modular MEICA built } \\
\text { off-site or civil asset assembly }\end{array}$ & Huber screen & $\begin{array}{l}\text { Standard } \\
\text { scalable design, } \\
\text { bespoke to site }\end{array}$ \\
\hline $\begin{array}{l}\text { Asset } \\
\text { reference } \\
\text { design }\end{array}$ & $\begin{array}{l}\text { Asset } \\
\text { reference } \\
\text { design }\end{array}$ & $\begin{array}{l}\text { Reference design for a major asset category based on the off- } \\
\text { site construction technique, with supporting building } \\
\text { information model (BIM) and design calculations, to be } \\
\text { expanded and amended for each like asset build }\end{array}$ & Service reservoir & Virtual \\
\hline $\begin{array}{l}\text { Minimum } \\
\text { asset } \\
\text { standard }\end{array}$ & $\begin{array}{l}\text { Minimum asset } \\
\text { standard }\end{array}$ & $\begin{array}{l}\text { Focused specification detailing particular minimum requirements } \\
\text { for a specific asset type, potentially accompanied by sketch or } \\
\text { general arrangement (GA) drawing }\end{array}$ & $\begin{array}{l}\text { Waste water treatment } \\
\text { work inlet screen } \\
\text { modified active sludge }\end{array}$ & Virtual \\
\hline $\begin{array}{l}\text { Standard } \\
\text { detail }\end{array}$ & Standard detail & $\begin{array}{l}\text { Drawing of acceptable arrangement for commonly recurring } \\
\text { asset assembly }\end{array}$ & Penstock detail & Virtual \\
\hline $\begin{array}{l}\text { Conventional } \\
\text { build }\end{array}$ & $\begin{array}{l}\text { Generic } \\
\text { standards and } \\
\text { specifications }\end{array}$ & $\begin{array}{l}\text { Suite of overarching specifications requiring the designer and } \\
\text { supply chain to make an interpretation of the exact } \\
\text { requirements for each asset type }\end{array}$ & Waste water treatment & Virtual \\
\hline
\end{tabular}


This problem will reduce with time as DFMA matures; however, this will require the successful delivery of projects to do so. A further enabler is the use of standard products which can provide high confidence at the tender stage. This stage could be argued to be a chicken-and-egg situation. Without proven track record and efficiencies, there would be hesitance to implement DFMA, but without implementing DFMA, there will never be a track record. This is compounded by suppliers within the industry often being slow at sharing knowledge. It is crucial that the industry, particularly from the client level, keeps pushing for DFMA as the wider benefits are reliant on the ability to demonstrate a commercial advantage (Table 2).

Despite the changes to UU's delivery model for AMP6, at the project level, the delivery model often leads to the short-term capital value of the project taking precedence. If the DFMA solution is not at the initial consideration, the cheapest, regardless of maturity, and the traditional solution inevitably wins.

\section{UU's standards and project delivery system}

To ensure that company processes did not stifle DFMA, a review of all relevant processes was undertaken. UU maintains a library of in-house standards and specifications. Asset standards detail minimum performance requirements providing a means of quality control across multiple projects. Below these standards sit UU's technical specifications and signature designs (Figure 8). These provide design templates which meet the asset standard. A review was undertaken to identify and remove DFMA blockers from these standards. The overarching engineering guidance document, asset standard design principles, was changed to state a preference for DFMA-delivered solutions.

A review of UU's project delivery system (PDS) identified key points within project life cycles where a DFMA approach was the most critical and added the most value. To support the PDS, new processes and project template documents were amended to facilitate a focus on DFMA. This included new clauses within the standard engineering scope template, a critical contract document. These changes require contractors to collaborate with the DFMA programme on the operation and sharing of DFMA intelligence, opportunities and successes.

\section{The DFMA library}

A critical enabler of knowledge sharing is the DFMA library. This enables knowledge sharing across organisations and project teams. Originally, a catalogue was envisioned to provide UU and its partners with a set of standard DFMA products. Product information would be readily available, empowering users in choosing the best-value products against their project-specific requirements and constraints. This would drive efficiencies across projects, reducing design and implementation durations and adding additional confidence in total project costs and operational performance.

The availability of AMP6 resources to develop standard products and populate this catalogue was limited. It became apparent that the catalogue was a long-term objective. To drive DFMA in AMP6, an alternative approach was developed to deliver benefits faster and provide a springboard for the future catalogue. Through collaboration with UU's partners, a DFMA library was created to share both proven and untested products. The key difference between the catalogue and the library is that the catalogue would contain only fully developed products that could be implemented from the information provided within it, whereas the library would contain information on products at varying levels of maturity. To identify product maturity, each product is given a level score of 1-4. A higher score reflects a greater level of product maturity and product-specific information. A level 4 product meets the information and maturity criteria suitable for a UU catalogue product (Figure 9).

Realistically not expecting level 3 and level 4 products immediately from UU's new supply chain, the authors encouraged basic intelligence (level 1) and examples of accepted DFMA (level 2).

The library is a live digital platform providing a source of knowledge, data and the best practice to approved users. Content,

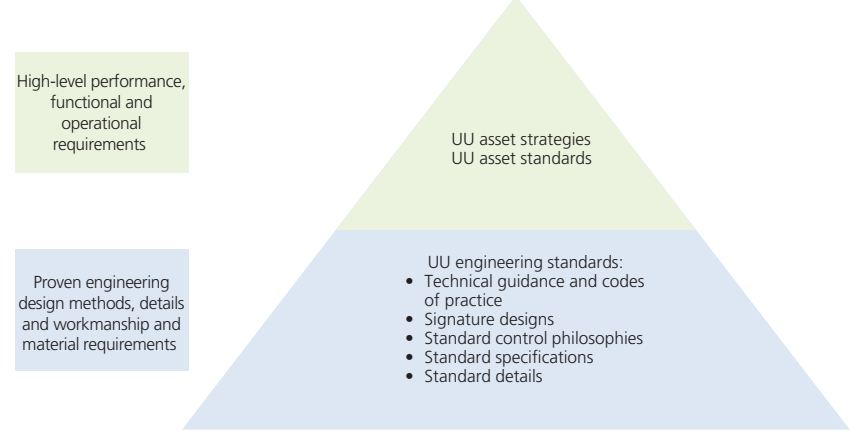

Figure 8. UU's in-house standard hierarchy

Table 2. Key differences between UU's AMP5 and AMP6 delivery models

\begin{tabular}{|c|c|c|c|c|c|}
\hline Period & $\begin{array}{l}\text { Main contract } \\
\text { model }\end{array}$ & Main tendering model & $\begin{array}{c}\text { Who designs the } \\
\text { solution }\end{array}$ & $\begin{array}{l}\text { Hands-on client } \\
\text { influence }\end{array}$ & $\begin{array}{c}\text { Willingness to } \\
\text { collaborate }\end{array}$ \\
\hline AMP5 & Alliance & Allocated workload & UU & High & Medium \\
\hline AMP6 & Design and build & $\begin{array}{l}\text { Mini competition with } \\
\text { framework }\end{array}$ & Supply chain partners & Low & Low \\
\hline
\end{tabular}




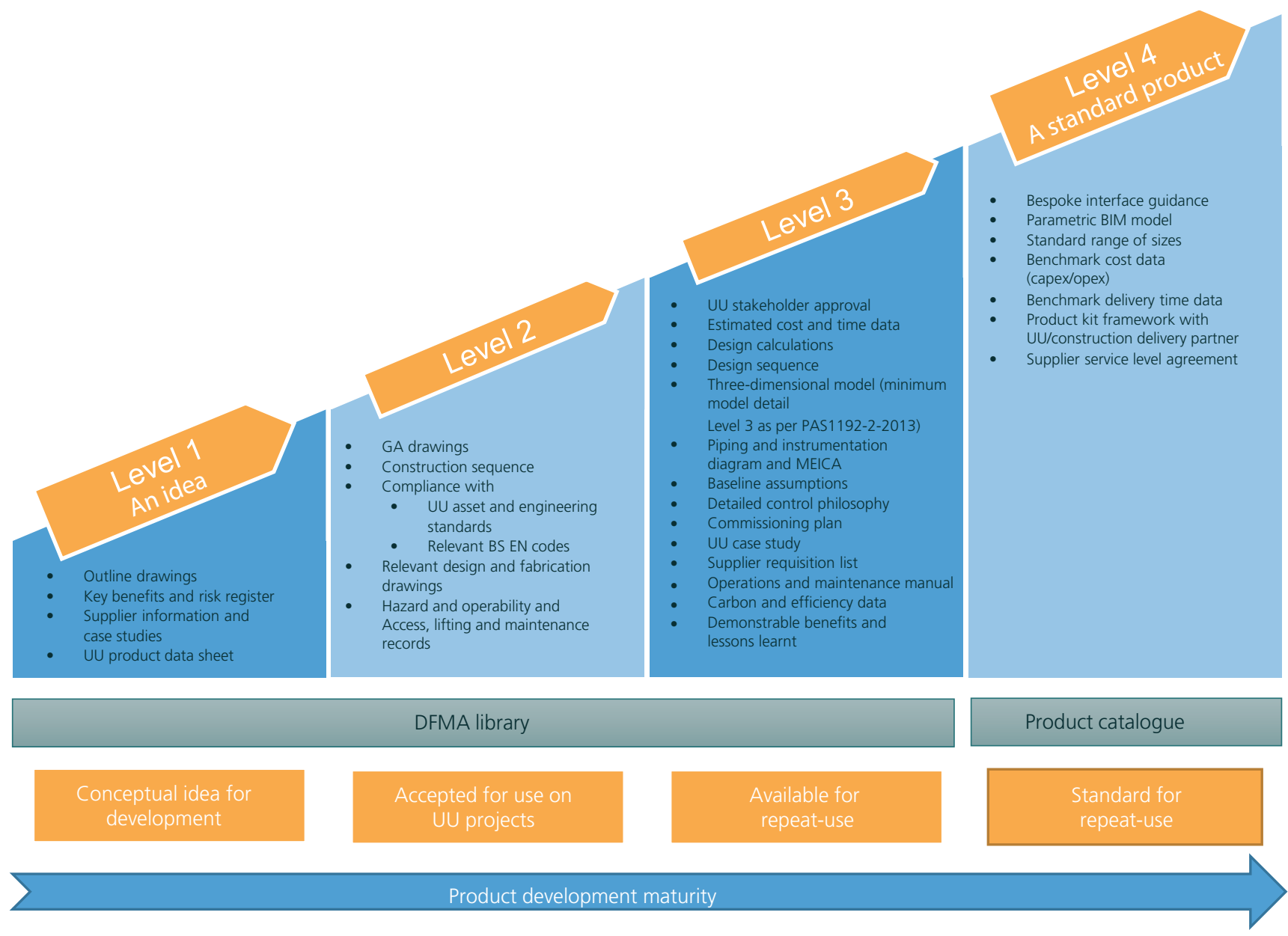

Figure 9. The DFMA library structure detailing how the amount of data associated with a product increases as it matures

approved by partners/engineering communities, can be added as and when new innovative solutions come onto the market. For level 1 , a case study template was created and used to standardise the information collected. This was designed to pull out the key benefits of the product, its application uses and past use. The template was intended to be concise to enable quick information capture without the need to consume a high resource level.

On projects, a robust workflow is applied based on BS 1192:2007 (BSI, 2007). This process was considered for use within the DFMA library but was recognised as overly complex for the level of work and risk associated with the level 1-3 products. Instead, an external simplified workflow specific to the DFMA library was created to manage the data collected. To populate the library, a develop-asyou-deliver approach was taken, where standard repeatable products would be developed on live projects in conjunction with some high-value products being developed offline.

\section{Standard product development}

To achieve the full benefits of DFMA, a greater use of standardisation is required. The DFMA programme set out to deliver standard products for use across the supply chain. Products were identified for development based on reuse potential across UU's investment programme, estimated cost benefits in comparison to a traditional solution and ease of development based on the availability of pre-existing DFMA solutions. This was further developed with input from UU's partners at the DFMA champions' workshops. Two approaches have been used to deliver DFMA products. First is online development, which develops a DFMA solution as an additional scope item on a live project. Second is offline development, which is the development of a DFMA product as a discrete project. The products are developed to provide the data requirements identified in the DFMA library for the desired product maturity level. The maturity level also indicates the extent of review required for UU sign-off. A review is undertaken using virtual teams for each product from asset management, engineering and operations.

\section{Communication and engagement}

Due to the varying levels of maturity within the industry and UU around DFMA, effective knowledge sharing of the best practices and lessons learnt was critical to building success. Knowledge 
A client's perspective of design for manufacture and assembly in the UK water industry

Trinder, Browne and Brocklebank sharing is a key part of the delivery strategy and was broken down into three key areas: (a) internal stakeholders, (b) supply chain and $(c)$ external bodies.

\subsection{Internal stakeholders}

The DFMA programme team engaged directly with internal stakeholders, including engineering, operations and supply chain, through ongoing presentations and briefings. To embed further, the programme centrally managed a multidisciplinary, multidepartment internal network of champions. These champions were supported by an internal internet portal and social media platform used to share DFMA-focused knowledge. For instance, case studies would be used to showcase successful DFMA and demonstrate the benefits it can deliver. The DFMA central team produced case studies in collaboration with the partners. These case studies were an important tool in gaining support from the project management community.

\subsection{Supply chain}

Collaboration with partners and the wider supply chain was through several channels including open days, knowledge-sharing events, targeted audience workshops, direct liaison, projectspecific intervention and company-wide communications. Each partner has a nominated senior member as a single point of contact who forms part of the DFMA champions' working group. The DFMA champions meet regularly to discuss progress and share knowledge. UU hosted supplier forums to champion DFMA, resolve challenges to success and bring innovation into the programme. These events encouraged wider supply chain engagement with UU. The DFMA team functioned as the central point of contact on DFMA matters. This single point of contact enabled efficient, targeted communication from the supply chain. To promote DFMA, UU, in collaboration with their partners, has been celebrating success. The programme plans to promote and incentivise further by introducing DFMA and innovation-focused awards which will reward positive DFMA behaviours.

\subsection{External bodies}

To better understand, influence and promote DFMA across the industry, UU worked with trade associations and professional bodies. UU supported Buildoffsite (2017) and their water hub to help lead industry change while working with the Offsite School (2017) to upskill capabilities. UU organised meetings to demonstrate the use of DFMA on UU projects including showcasing of the major work undertaken by Laing O'Rourke on the Davyhulme modernisation project in Manchester (Figures 10 and 11). UU also contributed at the national level in conjunction with the professional bodies including hosting Institution of Civil Engineers regional seminars and supporting evening lectures.

\section{Monitor}

Information was tracked to $(a)$ identify opportunities, $(b)$ remove barriers, $(c)$ track and review progress and $(d)$ share knowledge.

Identify opportunities. The supply chain identifies opportunities at the project concept stage and shares this with

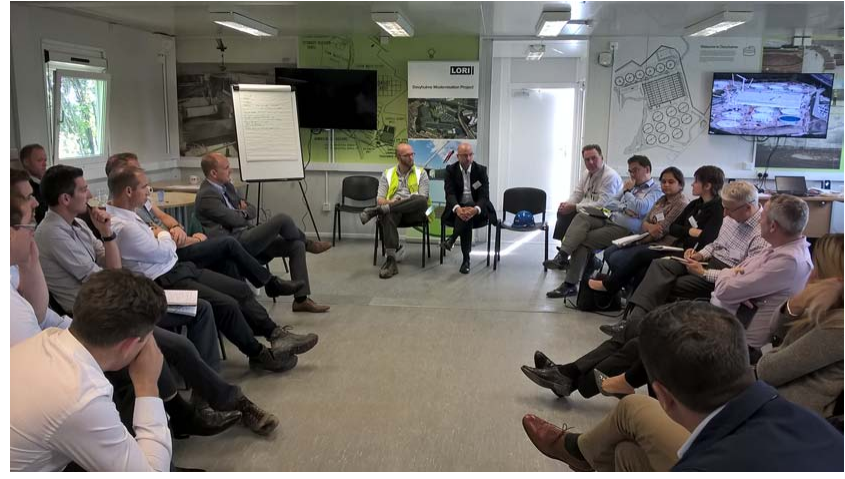

Figure 10. Photograph taken during the build-off-site workshop during an event at the Davyhulme modernisation project

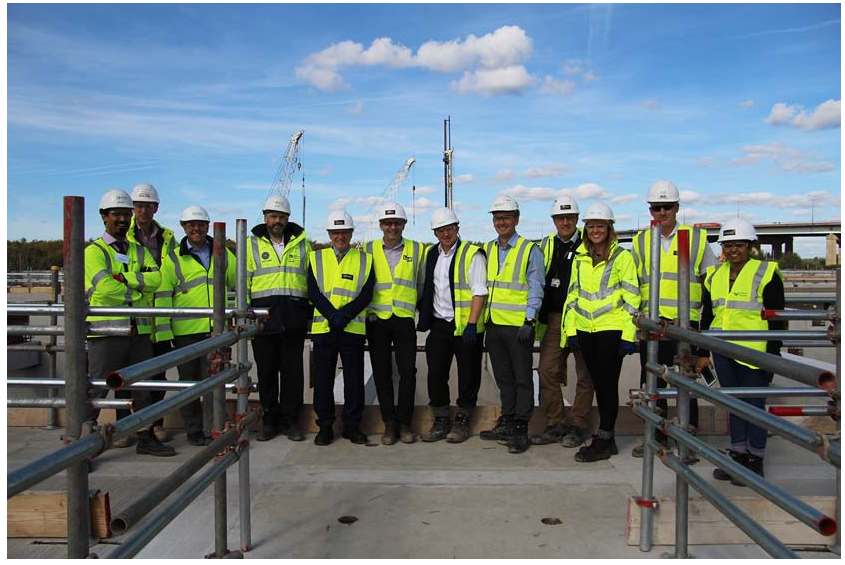

Figure 11. Photograph taken during the build-off-site site tour at the Davyhulme modernisation project

UU. This enabled real-time tracking of upcoming projectspecific DFMA benefits with a focus on cost and time.

- Remove barriers. To support the technical governance required by UU's PDS and reduce the scheduling risks associated with tender review periods, the DFMA programme undertook pre-emptive product reviews. By identifying innovative products prior to their proposed use on tenders, the DFMA programme could support their development and increase their suitability for UU projects. Without this upfront review, innovations can be missed due to the timescales required to review them and collect suitable data during live projects.

- Track and review. The DFMA opportunity tracker is reviewed internally by UU's DFMA programme team and the DFMA champions. The DFMA tracker is submitted at key project milestones including contract awarding and project completion. The final project's complete register provides information for recording the actual benefits delivered.

- Knowledge sharing and collection. Identification of potential use of DFMA developed UU's market knowledge. This 
enables UU to identify missed opportunities by referring back to other projects where a DFMA product had been used.

A greater awareness of products supports repeated use across UU's programme.

The tracker was developed by the DFMA team supported by UU's partners. The tracker needed to be simple and quick to use but also detailed enough to provide useful information. The tracking spreadsheet was designed to enable its information to be analysed and displayed as a management dashboard. This information is used as a reporting tool for senior leadership (Figure 12). This process captured the benefits with a breadth and depth of data not available before. This has reinforced the supporting evidence that DFMA brings not only financial but also time efficiencies.

The log completed by each partner is updated every 3 months. To embed the opportunity log within projects, it became a required deliverable within project-specific contracts and compliance was a key performance measure within the incentivised innovation KPI. This provided important management data, particularly useful not only within the DFMA champions' forum but also to individual project teams. Opportunity tracking allowed high-level benchmarking and comparisons between the partners and against programme goals.

\section{Outcomes}

Tracking has provided a significant amount of information over the past 2 years, and the volume of incoming information is accelerating as the investment programme hits its peak. A picture is appearing which supports the use of DFMA and shows DFMA becoming business as usual.

An initial target was to save 5000 person-days from the investment programme based on estimates from the AMP5 programme. This was chosen on the basis that less work on-site would improve safety and quality and reduce environmental,

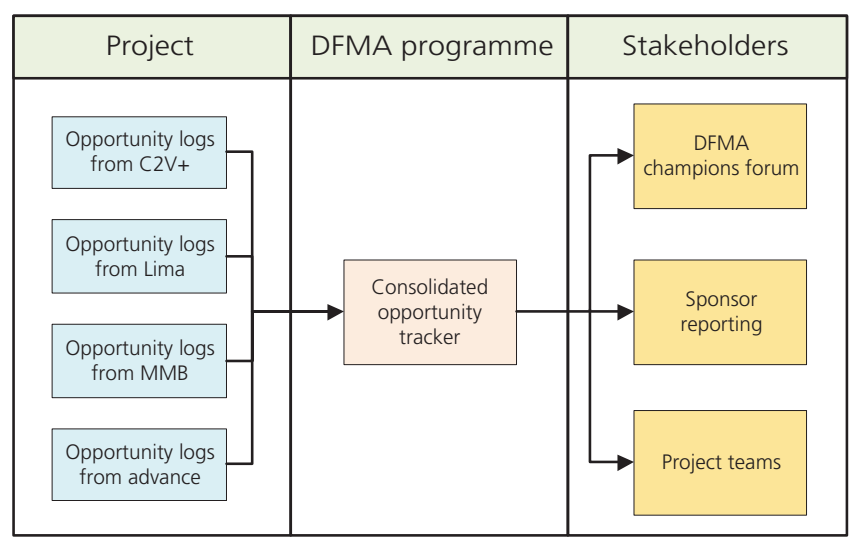

Figure 12. High-level schematic diagram detailing the flow of data between parties involved in delivering projects at UU operational and customer impacts. The indirect cost implications of less time on-site are difficult to measure directly, and time saved has not been converted by the DFMA programme to a financial metric. The programme had already exceeded this time target by the end of year 2 and is now looking towards a more ambitious $20000 \mathrm{~d}$ by the end of the AMP6.

Cost data show that the DFMA programme has delivered efficiency savings. In the 82 awarded projects, one-third of the total expected number of projects to be delivered in AMP6, project teams are working to deliver $£ 14$ milion of savings. UU is on target to reach $£ 50$ million by 2020 as there are several highpotential, high-value projects yet to be awarded.

\section{Reflections}

UU's AMP6 DFMA programme, now in its third year, has succeeded in promoting and encouraging the use of DFMA. It is still working to embed further DFMA use, has captured and shared many lessons learnt and is continuing improvement and upskilling (Figure 13). DFMA has become more of an expected business-as-usual approach and is now on more than $80 \%$ of UU construction projects.

UU has a planned programme of work, but one subject to change. The level of detail within it permits only high-level estimates of repeated product use across individual projects. Delivering repeated use across the programme was difficult and not fully exploited by UU. Lessons learnt from AMP6 will be used to make better use of the programme in AMP7.

Achieving product standardisation across UU's partners has proven difficult. Each partner has different business structures,

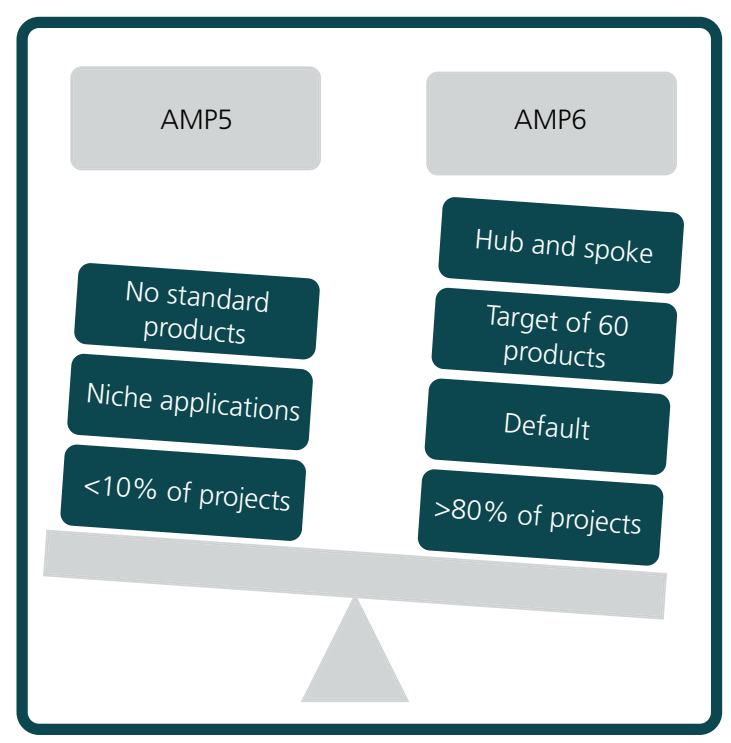

Figure 13. Schematic diagram highlighting the key deliverables achieved by the DFMA programme at UU by comparing DFMA use between AMP5 and AMP6 
which influence the potential to use and benefit from specific products. For example, one partner may have a direct labour force that specialises in in situ concrete, which must be adequately fed work to remain viable, whereas another partner may own manufacturing capability, preferring to do everything off-site.

The outline plan for products and DFMA was for the partners to offer up solutions and the client to accept; simplistically, there has not been enough offered for the client to accept.

A design-and-build contract provides opportunity for partners to optimise design. On projects where UU requires challenging process, guarantees can, in some instances, put significant risk on the partner. This inevitably influences the partners to become more risk-averse, reverting back to proven technologies and site processes. It can be argued that UU's design-and-build framework drives behaviours that limit knowledge sharing between partners. By awarding a significant percentage of work through competition, partners are reluctant to share innovative solutions outside of specific, awarded projects to retain their competitive advantage.

The benefits associated with DFMA go beyond design and construction. These benefits are less defined and less appealing to an industry that focuses on short-term project outcomes. These are not recognised to the same extent as project-focused time and cost metrics critical to project teams. The data collected by the DFMA programme will help to address this.

During AMP5, UU had a broad range of contracts for standard equipment. Though this provided consistency, security of supply and cost certainty, it was perceived to be a blocker to innovation. A move to fewer frameworks in AMP6 has in some cases helped enable greater use of the wider supply chain. However, the design-and-build contract strategy reduces the extent to which UU can influence the use of specific products that are not covered by equipment frameworks (e.g. pumps). As the programme continues to deliver successful DFMA products and mature, there is likely to be a case for new product-focused kit frameworks for highvalue DFMA solutions. This would facilitate a move towards a catalogue of solutions, a long-term DFMA programme goal.

The in-project approach enabled UU to develop DFMA products at less cost compared to offline product development. However, the development of standard products was not as fast as planned. In-project product development was dependent on project-specific schedules. It also required partner engagement and commitment to the long-term value of shared repeated use when individually, they would have limited visibility of long-term programme needs.

The original DFMA strategy was based on a greater planned baseload of projects being awarded early within years 1 and 2 of AMP6. This was not readily achieved, and product development was affected. As the AMP was planned to have the majority of the work awarded in years 2 and 3, the majority of the DFMA products were ultimately expected in year 3 and beyond. To value DFMA efficiencies, it was agreed that benefits could only be demonstrated through completion of projects and built assets.

There has been a cultural shift within UU, creating a level of expectation and demand for DFMA, but this has been tempered by the number of business change initiatives undertaken as part of the move from the AMP5 to the AMP6 delivery model. The DFMA programme expects this cultural shift to accelerate as the AMP progresses and people become more familiar with new processes. The library system and frequent DFMA champions' meetings facilitate the sharing of lessons learnt between partners. However, ensuring the right people get the right information both internally at UU and through the supply chain is difficult.

A pillar of the original strategy was the collaborative and open sharing of knowledge across the partners and wider industry. It became apparent that the industry is not incentivised to share, be it at the local or the national level; there is limited formal sharing of knowledge outside of individual personal relationships. UU agreed with AMP6 partners that for an innovation's first use, the originating partner would retain competitive advantage, but once successfully installed, UU would be able to share with the rest of the partners. This approach did not work well within the delivery model due to the ongoing competition, resulting in partners' reticence to share the best solutions before projects had been completed. This limited development speed and sharing of intelligence. To mitigate this, the DFMA team worked openly with organisations such as Buildoffsite and the Offsite School; however, the speed of change is such that the benefits of knowledge sharing have yet to be achieved.

\section{Conclusion}

The client-led DFMA programme has successfully enabled and proved the breadth of efficiencies that DFMA can deliver. However, the DFMA programme has not yet achieved its full potential due to the limited workload, contract model and use of standardisation and repetition. Although UU created an environment seemingly ripe for standardisation, time and cost challenges led to delivery behaviours reverting to traditional approaches.

Due to the low margin and high process risk, the sector could be perceived as having had a subconscious culture of needing to be followers and not innovators. Unless there are clear justifiable short-term benefits, the sector struggles to adopt new technologies that can deliver long-term benefits. Due to the lack of industry maturity in DFMA, any failures or issues fuel the fire of sceptics. In an industry with single-digit margins, collective, collaborative and sustained effort is required to overcome initial development costs and risks.

To shift fully from a traditional project delivery model to a DFMA approach, a business- and industry-wide culture change is required. The success of DFMA relies on asset owners, engineers 
and the supply chain choosing to use it and understanding where it is appropriate and where it is not.

Clients are cautious of adopting unproven DFMA products, and without trialling these products, it is difficult to collect the evidence to support them. To maximise the potential benefits, a commitment to deliver by way of DFMA is required early. The focus on short-term deliverables on individual projects combined with a lack of consideration of the long-term programme-level benefits has been a blocker. This could be overcome with a collaboratively planned programme of works that provides volume not only to spread the risk but also to refine the solution. This appears contrary to a design-and-build model where individual projects are awarded, not batched.

As competition enters the water industry and regulatory and cost commitments become more challenging, more companies will seek the efficiencies available through DFMA. As the DFMA programme gathers ever more information supporting these benefits, the culture change will become less challenging as project and programme managers begin to seek DFMA delivery methods proactively. With ever-increasing demand from clients, the supply chain will receive the demand and incentive to innovate further with DFMA and move towards industrial construction.

The following is a summary from the client's perspective.

- Awarded projects - these are not enough against the original plan.

- Reach - have all parts of the capital programme been reached?

- Whole-life cost - DFMA is not always the lowest capex, but time, safety and customer benefits make it the best-choice option.

- Design and build - this is limited in encouraging programme benefits.

- Standard product - this is not readily available or shared across the supply chain.
- Best practice - this is not transferred by the supply chain internally.

- Innovation - this is not offered easily/not outperformed by the kit framework.

- Develop-as-you-deliver approach - it needed capital and stability.

\section{Recommendations for future work}

There have been many successes and lessons learnt collected through this programme, and more are expected to be realised as projects reach completion. From the work completed to date, the following recommendations are proposed to embed further and deliver the benefits of DFMA, from the client's perspective, within the UK water industry.

- Collect and share robust, comparable whole-life cost and time data on the use of DFMA in comparison to traditional builds.

- Design, manufacture and assembly and supply chain engagement should be done earlier, coupled with better longterm visibility of projects.

- Deliver programmes of work based on functional batch increasing the opportunities to repeat.

- Encourage and develop an environment within the UK which promotes and incentivises greater client-level collaboration and standardisation.

- Encourage and develop a platform across the industry to recognise and reward innovation. This should include instruments that enable fairer sharing and allocation of risk between parties.

\section{REFERENCES}

BSI (2007) BS 1992:2007: Collaborative production of architectural, engineering and construction information - code of practice. BSI. London, UK.

Buildoffsite (2017) http://www.buildoffsite.com/ (accessed 12/12/2017)

Offsite School (2017) https://www.supplychainschool.co.uk//uk/offsite/ construction/default.aspx (accessed 12/12/2017).

\section{How can you contribute?}

To discuss this paper, please email up to 500 words to the editor at journals@ice.org.uk. Your contribution will be forwarded to the author(s) for a reply and, if considered appropriate by the editorial board, it will be published as discussion in a future issue of the journal.

Proceedings journals rely entirely on contributions from the civil engineering profession (and allied disciplines). Information about how to submit your paper online is available at www.icevirtuallibrary.com/page/authors, where you will also find detailed author guidelines. 